\title{
La escuela técnica y la formación profesional desde una perspectiva de género en la provincia de Corrientes (Argentina)
}

The technical school and professional training from a gender perspective in the province of Corrientes (Argentina)

Volumen 19, Número 3

Setiembre-Diciembre

pp. 1-26

\section{Ana María D'Andrea María Paula Buontempo}

Citar este documento según modelo APA

D’Andrea, Ana María y Buontempo, María Paula. (2019). La escuela técnica y la formación profesional desde una perspectiva de género en la provincia de Corrientes (Argentina). Revista Actualidades Investigativas en Educación, 19(3), 1-26. Doi. 10.15517/aie.v19i3.38630 


\title{
La escuela técnica y la formación profesional desde una perspectiva de género en la provincia de Corrientes (Argentina)
} The technical school and professional training from a gender perspective in the province of Corrientes (Argentina)

\author{
Ana María D'Andrea' \\ María Paula Buontempo 2
}

Resumen: Históricamente la educación técnico-profesional se caracterizó por presentar rasgos de discriminación sexista y por reproducir la división sexual del trabajo cristalizada culturalmente. No obstante, las mujeres se fueron introduciendo de manera gradual en este tipo de oferta educativa. El objetivo de este artículo es comparar cómo se presenta la perspectiva de género en escuelas secundarias técnicas y centros de formación profesional en cuanto a los motivos que incidieron en la elección de los mismos, la valoración de la formación recibida y las expectativas futuras. Se trata de un estudio cualitativo de alcance descriptivo realizado a finales del 2017 . Se utilizan grupos focales, con varones y mujeres por separado, de una muestra intencional de tres escuelas técnicas que tienen ofertas de educación secundaria y formación profesional de la provincia de Corrientes (Argentina). Respecto a los motivos que incidieron en la elección de la modalidad, no se encuentran diferencias en varones y en mujeres. En cuanto a la valoración de la formación recibida, el estudiantado de secundaria percibe propuestas educativas diferenciadas según género, lo que es considerado discriminatorio por parte de las mujeres. Acerca de las expectativas futuras, todos coinciden en que las mujeres no tendrán las mismas oportunidades laborales por más que tengan la misma certificación. Se concluye que la principal diferencia entre cursantes varones y mujeres de educación secundaria y de formación profesional es la mayor percepción respecto a los derechos adquiridos en los últimos tiempos que tienen las mujeres más jóvenes. Así, las influencias de los movimientos feministas en la Argentina atraviesan los poros de instituciones tan tradicionales como las educativas.

Palabras clave: perspectiva de género, enseñanza técnica, formación profesional, igualdad de oportunidades

\begin{abstract}
Historically, technical-professional education is characterized by presenting the characteristics of sexual discrimination and the sexual part of culturally crystallized work. However, women have been introduced gradually in this type of educational offer. The objective of this article is to present the perspective of gender in technical secondary schools and vocational training centers in terms of the reasons that influenced the choice of the same, the evaluation of the received training and future expectations. It is a qualitative study of descriptive scope carried out at the end of 2017. Focus groups were used, with men and women separately, from an intentional sample of three technical schools that have offers of secondary education and professional training from the province of Corrientes (Argentina). About the reasons that affect the choice of modality, no differences are found in men and women. Regarding the evaluation of the training received, the study of secondary education refers to educational differences differentiated according to gender, which is considered discriminatory by women. About future expectations, everyone agrees on women. It is concluded that the main difference between male cursors and women in secondary education and vocational training is the majority of the rights acquired in recent times by younger women. Thus, the influences of feminist movements in Argentina go through the pores of institutions as traditional as educational ones.
\end{abstract}

Key words: gender perspective, technical education, vocational training, equal opportunity.

\footnotetext{
${ }^{1}$ Docente-investigadora de la Universidad Nacional del Nordeste, Facultad de Humanidades; Ministerio de Educación de la Provincia de Corrientes, Argentina. Dirección electrónica: anadandrea@gmail.com

2 Docente-investigadora de la Universidad Nacional del Nordeste, Facultad de Humanidades; Ministerio de Educación de la Provincia de Corrientes, Argentina. Dirección electrónica: buontempop@gmail.com
}

Artículo recibido: $1^{\circ}$ de octubre, 2018

Enviado a corrección: 8 de mayo, 2019

Aprobado: 10 de junio, 2019 


\section{Introducción}

Actualmente, en la Argentina, las mujeres acceden a niveles educativos superiores a los hombres, pero esto no se ha traducido en un aprovechamiento en términos de una inserción laboral y remuneración equitativas. Con un índice de masculinidad del 94,8\% según el último censo, el número de mujeres supera al de los varones en el país (Gobierno de Argentina, Instituto Nacional de Estadísticas y Censos [INDEC], 2012). Esto significa que la consideración de la igualdad de oportunidades laborales implica no solamente un reconocimiento a los derechos de las mujeres, sino también el aporte que éstas pueden hacer al sistema productivo.

En la modalidad que intenta articular educación y trabajo, como es la Educación Técnico-Profesional (ETP), según información del Instituto Nacional de Educación Tecnológica (INET), la matrícula femenina creció en este siglo. Sin embargo, continúa evidenciándose una proporción mucho mayor de estudiantes varones que de mujeres. Las alumnas matriculadas en la ETP (formación profesional, secundario técnico y superior técnico) representan el $43 \%$ del total. Este porcentaje todavía es menor en la Escuela Secundaria Técnica (EST), ya que solo el $32,5 \%$ son mujeres; en cambio, en Centros de Formación Profesional (CFP), dicho porcentaje asciende al $56 \%$ y en las tecnicaturas superiores al 60,5\% (INET, 2018).

Este trabajo forma parte de un estudio mayor realizado en los años 2017-2018, cuyo objetivo fue analizar cómo se producen y reproducen, a nivel institucional, las desigualdades entre varones y mujeres, e identificar las acciones tendientes a promover la igualdad de género en EST y CFP de la Argentina. Se trató de una investigación descriptiva con un enfoque mixto donde se utilizaron múltiples fuentes, tanto primarias como secundarias, así como técnicas cualitativas y cuantitativas para construir los datos correspondientes.

En estas páginas se presentan los principales resultados de los grupos focales realizados con cursantes (varones y mujeres por separado) de tres escuelas técnicas (ET) de la provincia de Corrientes. Las tres ofrecen ciclo básico y ciclo superior de educación secundaria, además, tienen anexo un CFP. El objetivo de este artículo es comparar, a partir de las reflexiones de dichas personas, cómo se presenta la perspectiva de género en las especialidades y en los cursos seleccionados, en relación con los motivos que incidieron en la elección de la escuela, la especialidad o el curso, la valoración de la formación recibida y las expectativas educativas, laborales y familiares. 
Si bien existen avances notables en políticas públicas referidas a cuestiones de género (varón, mujer, otros), se pone el foco en las mujeres porque se considera que es una temática que ocupa uno de los lugares principales en la agenda actual de la política educativa, y porque aportar reflexiones sobre esta temática resulta fundamental para analizar los mecanismos institucionales a través de los cuales las desigualdades se cristalizan en mandatos y destinos socialmente esperados para varones y mujeres. Con esto, también se pretende contribuir con los estudios vinculados a los Objetivos de Desarrollo Sostenible (ODS) de la Organización de las Naciones Unidas (ONU), los cuales plantean la transversalización de la perspectiva de género como herramienta metodológica para valorar políticas y legislaciones desde el punto de vista de sus implicaciones sobre varones y mujeres.

\section{Referentes teóricos}

\subsection{La perspectiva de género en la matriz de la educación técnico-profesional}

La educación técnica argentina se gestó a fines del siglo XIX y se consolidó a principios del siglo XX. En sus orígenes tenía dos tipos de destinatarios: las escuelas industriales eran para varones y las escuelas profesionales para mujeres. Ambas estaban orientadas a quienes deseaban tener una salida laboral inmediata y no querían o no podían continuar estudios superiores. Con el tiempo, los objetivos primigenios fueron variando, así como los perfiles de las escuelas técnicas. En 1964, se unificaron las escuelas industriales con las escuelas fábricas para varones, y las profesionales y de fábrica para mujeres en una sola denominación: Escuela Nacional de Educación Técnica (ENET) (Sobrevila, 1995).

Las primeras escuelas profesionales destinadas a mujeres tenían por función prepararlas para cumplir un rol fundamental como protectoras del hogar (Seoane, 2013). En los años setenta del siglo XX, comenzaban a ver disminuida su matrícula en virtud de la incorporación de las mujeres al mercado de trabajo y de nuevas expectativas y demandas. Es por eso que muchas de ellas adoptaron la especialidad Administración de Empresas para prepararlas en ocupaciones de oficina del sector terciario de la economía (Gallart, Miranda, Peirano y Sevilla, 2003).

En el 2005, la Ley de Educación Técnico-Profesional (LETP) destaca, en el artículo 40, que "se ejecutará una línea de acción para promover la incorporación de mujeres como alumnas en la educación técnico-profesional..." En este marco, actualmente se observa un 
crecimiento de la matrícula femenina, tal como señalamos anteriormente (Ley № 26.058, 2005).

En el 2018 se crea la Comisión de Género en el marco de la ETP. Este organismo tiene como objetivo incorporar la perspectiva de género e incrementar el número de mujeres en la modalidad, en lo que se refiere al alumnado, al equipo docente y directivo.

Las mujeres en las escuelas técnicas aparecen para ciertos grupos como "la otredad", ya que sus elecciones educativas en esta modalidad son concebidas como rarezas en algunas especialidades, principalmente aquellas consideradas masculinas (Bloj, 2017). Seoane (2013) sostiene que la escuela, al igual que las instituciones que forman el entramado social, socializa a las nuevas generaciones en un determinado sistema sexo/género en el que la mayoría de las veces se reproducen (descuidadamente o no) desigualdades y visiones estereotipadas respecto de lo femenino y lo masculino y, en otras, se habilitan espacios para debatir y desnaturalizar los mandatos sociales que recaen sobre mujeres y varones.

Dicha autora, también apuesta a la hipótesis de que la matriz fundacional de la escuela técnica funciona como contenido fundamental de la socialización escolar. Esta matriz, en ocasiones, estigmatiza y discrimina al estudiantado por su condición social, juvenil, sexual y étnica, como también construye un sentido de pertenencia que lo diferencia de aquellos que asisten a otras escuelas (Seoane, 2012). Así, el sexismo y el androcentrismo son formas de discriminación, y como práctica están presentes en las instituciones educativas y forman parte de la socialización de las nuevas generaciones (Morgade, 2001). Según el Diccionario de estudios de género y feminismo, el sexismo se define como "el mecanismo por el que se concede privilegio a un sexo en detrimento de otro" (Gamba, 2007, p. 293). Es necesario para que se produzca lo que se define como androcentrismo: "la concesión del privilegio al punto de vista del hombre" (Gamba, 2007, p. 293).

La normativa argentina promueve el desarrollo de saberes que facilitan la inserción laboral de las mujeres y la promoción de movilidades horizontales y verticales en el mercado laboral. En este marco, se ha propuesto el desarrollo de estrategias para "desnaturalizar" las opciones profesionales por género (especialmente a partir de la orientación socio-laboral y de la construcción de un proyecto ocupacional realizable), revisando mandatos impuestos por la cultura. De este modo, se incorpora en la ETP la concienciación de los derechos de la mujer, propiciando la revisión crítica de los de roles diferenciados según género (Silveira, 2001, 2011). 
Investigaciones muestran que, en algunos casos, la ETP ha incorporado estrategias que reconocen la perspectiva de género como ser la inclusión de mujeres en ámbitos en los cuales han estado sub-representadas históricamente, la incorporación de acciones de deconstrucción de la desigualdad de género, mediante una revisión reflexiva y crítica de la división sexual del trabajo (Millenaar, 2016) y el programa nacional de Educación Sexual Integral (ESI) que supone un avance en materia de incorporación de contenidos en la escuela (Lavigne, 2009).

Dichas investigaciones se complementan con otros trabajos sobre las desigualdades de género en la ETP, que indican ejes de indagación fundamentales para este estudio: se señala que la composición del cuerpo docente según sexo, y la división sexual del trabajo académico son importantes en la reproducción (o cuestionamiento) de estereotipos (Conde, 2013), y que las perspectivas del plantel docente en torno a las diferencias de género influyen en el currículo oculto. También, se manifiestan algunas resistencias desde distintos sectores a la implementación del programa de ESI. Así, el género resulta, aún, un factor de desigualdad persistente y difícil de revertir.

\section{Metodología}

\subsection{Enfoque}

En este artículo se presentan los principales resultados de los grupos focales realizados con cursantes (varones y mujeres por separado). El objetivo fue comparar, a partir de sus reflexiones, cómo se presentaba la perspectiva de género en las especialidades y los cursos seleccionados, en relación con los motivos que incidieron en la elección de la escuela, la especialidad o el curso, la valoración de la formación recibida y las expectativas educativas, laborales y familiares. Se trató de un estudio cualitativo de alcance descriptivo.

\subsection{Población en estudio}

Se realizó la selección intencional de tres ET a partir de los siguientes criterios: 1) la distribución de la matrícula de estudiantes según sexo, 2) la historia institucional, 3) la localización geográfica y 4) la importancia del sector productivo.

Así la muestra quedó constituida por tres EST con sus respectivos CFP, dos de la capital y una del interior de la provincia de Corrientes. Las tres difieren en cuanto a antigüedad. La ET 1 data de principios del siglo XX (1924), la ET 2, de mediados del mismo siglo (1948) y la ET 3, de fines del siglo XX (1975). Además, se diferencian por el tipo de 
formación que brindan (en cuanto a especialidades de educación secundaria y cursos de FP) y por tener un origen distinto. Esto último resultó definitorio para la selección de las EST porque la ET 1, en sus orígenes, estuvo destinada a la formación de mujeres; la ET 2, a la de varones; y la ET 3 siempre fue mixta. Aunque las dos primeras se convirtieron en mixtas a partir de la década del 70 del siglo XX.

En la actualidad, las tres ofrecen ciclo básico y ciclo superior de educación secundaria, además, tienen anexo un CFP. De las especialidades del ciclo superior, se consideraron para esta investigación: Informática, Industrialización de la madera y el mueble, y Administración y gestión de las organizaciones. Por su parte, de los cursos de FP: Armado y reparación de PC, Operador de moldurera y Carpintero de banco.

Los sectores Informática (Informática y Armado y reparación de PC) y Madera y Muebles (Industrialización de la Madera y el Mueble, Operador de Moldurera y Carpintero de banco) fueron elegidos porque constituyen espacios con una importante potencialidad para la inserción laboral en la provincia de Corrientes, además de que son áreas de vacancia para la generación de ofertas (INET, 2016; Tavela y Cantilo, 2018). Se incluyó, asimismo, un tercer sector: Administración (Administración y Gestión de las Organizaciones) siguiendo el criterio de selección de los casos (distribución de la matrícula según sexo).

Para recuperar las voces de las personas participantes, se llevaron a cabo grupos focales con varones y mujeres por separado. Los cursantes de la EST eran del último año de la especialidad elegida y los del CFP eran la totalidad. En total fueron 55 estudiantes (29 varones y 26 mujeres). No se consideraron a quienes estaban ausentes el día del trabajo de campo. Se mantuvo el anonimato de las personas participantes.

\subsection{Técnicas de recolección}

El uso de grupos focales permitió indagar las características personales y familiares, las experiencias respecto a las dinámicas institucionales y de género, así como también relevar los motivos de la elección de la escuela, especialidad o curso, la valoración de la formación recibida y sus expectativas educativas, laborales y familiares.

Los temas sobre los que se conversó estuvieron organizados en bloques: significados asociados a la especialidad, valoración de la formación recibida, diferenciación por género en la EST o en la FP, visión del mercado laboral, expectativas futuras. En el caso de la EST, se apeló a la utilización de afiches para promover la discusión respecto a cómo es ser varón o cómo es ser mujer en esa especialidad, en esa EST. Y en el caso de la FP, la pregunta 
inicial hacía referencia a qué tenían que dejar organizado antes de ir al CFP y qué tenían pendiente al salir del curso.

\subsection{Procesamiento y análisis}

Los intercambios de los grupos focales fueron grabados y luego transcriptos para ser procesados con el software Atlas Ti versión 7. Se segmentaron frases como unidades de significado, identificando las categorías emergentes e incluyéndolas luego en las categorías principales.

Las categorías principales surgieron de los objetivos: motivos que incidieron en la elección de la escuela, la especialidad o el curso, valoración de la formación recibida y expectativas educativas, laborales y familiares. Los motivos tenían que ver con las razones que movieron a los estudiantes a elegir la especialidad y la escuela técnica. La valoración de la formación recibida era una evaluación que el grupo de estudiantes/cursantes realizaba de su paso por la institución. Y las expectativas futuras, como señala Córica (2015), permitieron relevar las condiciones que visualizaban como posibles y las oportunidades que proyectaban como realizables.

La categoría emergente más importante que surgió en los grupos focales fue la identificación del taller como el espacio privilegiado del aprendizaje y distintivo de la formación técnico-profesional.

\section{Resultados y análisis}

\subsection{Escuela secundaria técnica}

El grupo de cursantes de EST considerado tiene un rango de edad que oscila entre los 18 y los 20 años, reside en la localidad donde se encuentra la institución educativa y vive con uno o los dos progenitores. La mayoría no trabaja (65\%).

\subsubsection{Motivos de elección de la escuela técnica y de la especialidad}

El principal motivo de elección de la especialidad es la rápida inserción laboral (sobre todo en el caso de las mujeres) y, luego, la vocación o motivación personal. Lo que se condice con resultados de otras investigaciones donde se observa que las personas jóvenes no siempre deciden estudiar por una cuestión vocacional, sino que responden más bien a factores económicos. Además, confirman que la decisión no es autónoma, sino que es el sistema las quien empuja a tomar esa determinación (Seoane, 2013; Sweet, 2014): 
Porque me parece útil... al ser que estamos en Corrientes que hay mucho para explotar así que vamos a tener inserción laboral (Estudiante mujer, EST 2).

Vengo de una familia de técnicos y eso desde un principio me dio curiosidad por saber lo que saben mi tío y mi hermano que se recibieron acá... Después escuché una charla de la tecnicatura y la verdad que me re gustó... (Estudiante varón, EST 2).

Además de la posibilidad de insertarse en el mundo del trabajo, consideran que esta educación les brinda una mejor preparación para seguir estudiando, aunque no siempre en carreras vinculadas con la que están realizando:

En relación al estudio, me gustaría recibirme de contador público, estudiar pastelería y personal trainer o estudiar marketing (Estudiante mujer, EST 3).

A mí me gustaría ser marinero y después seguir estudiando (Estudiante varón, EST 2).

La totalidad de las mujeres de una de las escuelas manifiesta la incidencia de directivos y profesores (varones) en la elección de la especialidad. En las tres escuelas, la mitad de las mujeres expresan la falta de apoyo familiar frente a la carrera elegida, e incluso, frente a la institución. En este sentido, se puede decir que para las personas adultas todavía hay carreras que son masculinas y carreras que son femeninas:

Yo quería elegir Electricidad pero me dijeron que había un cupo limitado, sólo de dos mujeres. Se inscribían las que querían pero sólo elegían dos (Estudiante mujer, EST 3).

A mí en mi casa no me dejaban. Mi papá me decía que Electrónica y Mecánica no eran para mujeres (Estudiante mujer, EST 1).

Mi papá, por ejemplo, no quería. Decía que esta escuela es de hombres. Y yo le decía que quería ir (Estudiante mujer, EST 2).

En el primer ejemplo se advierte que, contrariamente a lo que realizan otras escuelas técnicas que tienen cuotas de participación con la intención de aumentar el número de mujeres (Millenaar, 2016), en esta escuela, la cuota es mínima y excluyente. En los otros dos ejemplos observamos que la diferencia entre lo que es considerado para mujeres y lo que es para varones viene de la socialización familiar, principalmente del progenitor masculino. Los relatos permiten confirmar que el modelo del patriarcado sigue vigente. Sin embargo, estas jóvenes resisten los mandatos sociales luchando, a partir de las decisiones que toman, 
contra el sistema de sexo/género imperante, mientras intentan mejorar su posición en el campo social, económico y familiar.

Entre los motivos de elección de la escuela técnica, también prevalecen, tanto en varones como mujeres, las "elecciones prácticas". Lo expresan de este modo:

Te permite reparar computadoras, programar... (Estudiante mujer, EST 1).

Cuando era chico veía Discovery y veía que hacían casas de madera y ése fue el primer incentivo... (Estudiante varón, EST 2).

Te enseñan a administrar una empresa (Estudiante mujer, EST 3).

Esta mirada es la que permite comenzar a entender la importancia otorgada a los talleres y la valoración que les atribuyen a las prácticas en el ámbito escolar, temas que se desarrollarán en los apartados siguientes.

\subsubsection{Valoración de la formación recibida}

El núcleo central de los contenidos de los que un técnico debe apropiarse en el transcurso de su formación está conformado por capacidades complejas. Dichas capacidades están vinculadas a conceptos, información, técnicas, métodos, valores y procedimientos, los cuales le permiten actuar e interactuar en diversos contextos. Además, suponen, tanto el dominio de conocimientos y habilidades técnicas propias de cada especialidad como el juicio para discernir y aplicar los recursos más convenientes en cada caso. Tanto varones como mujeres valoran positivamente la formación recibida en la escuela técnica, sobre todo la parte práctica, por cuanto adquieren capacidades que les permiten desempeñarse en sus propios hogares así como iniciarse en el ámbito laboral:

Entrevistadora: En relación a los espacios de talleres, ¿qué aprendieron?

Estudiante: De primero a tercero hicimos palas, percheros, porta-vinos, ceniceros, un montón. Teníamos muchas opciones, carpintería, herrería, computación, etcétera. Hasta nos enseñaron a soldar. Eso está bueno porque a la mujer la hace más independiente saber hacer todo eso.

Entrevistadora: Entonces se puede decir que en los talleres hubo como dos momentos, antes y después de tercero. ¿Y lo que viene después de tercer año?

Estudiante: Esto ya iba más orientado (Estudiante mujer, EST 1). 
La valoración que el estudiantado otorga a los talleres está asociada a lo manual, no a los procedimientos cognitivos que se ponen en juego cuando se hacen, por ejemplo, programación o balances. Esta consideración es una consecuencia de la mirada institucional. Así, las posiciones más críticas fueron de estudiantes de ambos sexos de las especialidades de Informática y de Administración y Gestión de las Organizaciones, para quienes las prácticas que llevan a cabo no son valoradas en la institución. Igualmente, plantean que no poseen espacios propios y/o específicos para poder desarrollarlas, ya que estos están destinados a las especialidades "más tradicionales":

Entrevistadora: ¿Cómo se podría mejorar el taller de informática?

Estudiante: Hacer algo en vez de venir y estar todo el día en la computadora (Estudiante mujer, EST 1)

Por ahí electricidad y mecánica hacen cosas más palpables. Ellos hicieron el auto solar, hicieron el semáforo, nosotros también hacemos cosas, lo que pasa es que no tenemos algo para mostrar (Estudiante mujer, EST 3).

Mecánica tiene taller, electricidad tiene taller, nosotros [Administración y Gestión de las Organizaciones] no tenemos. Tenemos que estar dando clases en otros espacios (Estudiante varón, EST 3).

Respecto a sus percepciones sobre el género en los espacios de taller, varones y mujeres se perciben en igualdad de condiciones. Sin embargo, aducen que los docentes de los talleres generan diferencias en función del tipo de tareas a desarrollar, vinculadas preferentemente con la fuerza. Este trato diferencial no es entendido como discriminatorio por los compañeros varones, sino que lo caracterizan como una cuestión de "caballerosidad" y "cuidado". Mientras que para las mujeres, sí, al no ser formadas en la práctica como los varones. Para Pérez Moreno (2013), el género es construido en medio de contextos sociales y culturales que producen múltiples formas de masculinidad y de femineidad, una de las cuales generalmente ejerce hegemonía sobre las otras:

Entrevistadora: ¿Qué implica ser hombre acá?

Entrevistado: Prácticamente lo que implica es lo de siempre, mucha fuerza.

Entrevistadora: ¿Pero ustedes por su propia forma de ser hacen lo más pesado?

Entrevistado: Si, por caballerismo.

Entrevistadora: ¿Por eso? ¿O porque piensa que las chicas no podrán?

Entrevistado: No, por caballeros. 
Entrevistadora: ¿Solo en el trabajo pesado?

Entrevistado: Si porque en los cortes, en los usos de máquinas le hacen hacer lo mismo. Yo creo que eso es lo que implica el ser hombre en una escuela técnica, que tenés que llevar las cosas pesadas (Estudiante varón, EST 2).

Nuestros compañeros [haciendo referencia a los varones] no hacen diferencias,...te acompañan, te ayudan en todo. Creo que los chicos son más atentos. En eso por ahí se notan más [las diferencias] en algunas actitudes que tiene un profesor en el taller (Estudiante mujer, EST 2).

A mí no me gusta, quiero hacer lo mismo... Por ejemplo, ahora estábamos en la construcción de la casa y yo no tengo problemas en poner la mezcla pero el profe nunca te va a mandar a hacer eso. Te dan una planilla para que registres (Estudiante mujer, EST 2).

Estos relatos permiten reforzar la idea de que el sexismo presente en las aulas y en las interacciones docentes-estudiantes es una parte del contenido que la escuela promueve. Según León (2009), en la EST abundan los registros de subestimación y desvalorización del personal docente y directivo sobre las alumnas, manifestados en las prácticas educativas. En muchos casos, se les prohíbe manipular máquinas o se les asignan tareas diferentes por el mero hecho de ser mujeres. No solo en la transmisión se reproduce un modelo sexista, sino también cada vez que se recortan las expectativas sobre las mujeres o cuando se magnifican, en función de una competencia entre los sexos, en la que las mujeres están obligadas a demostrar que su rendimiento es análogo al de los varones (Seoane, 2013):

Yo siento que es, como para que no te lastimes, porque tenemos que estar llevando vigas de un galpón a otro y te dicen "No, llevá una que te vas a forzar". Y yo de caprichosa llevo tres (Estudiante mujer, EST 2).

Así, se observa que los códigos de género se manifiestan principalmente en los talleres a través del lenguaje, las prácticas de enseñanza y el modo en que se relaciona el estudiantado.

Sumado a esto, estudiantes de ambos sexos valoran la socialización con sus pares. Dubet (2006) señala que las experiencias más importantes para la juventud ocurren en los intersticios de las instituciones, donde tienen lugar relaciones de sociabilidad, por lo que las 
escuelas de nivel secundario (tanto las técnicas como las escuelas secundarias orientadas) se convierten en los lugares privilegiados de la vida juvenil. Así lo expresa una estudiante:

[Valoro] la experiencia de compartir con compañeros [refiriéndose a ambos sexos] (Estudiante varón, EST 1).

Fui muy feliz con mis compañeros [tanto varones como mujeres], casi conviví con ellos (Estudiante mujer, EST 3).

\subsubsection{Expectativas educativas, laborales y familiares}

Respecto a las expectativas futuras de formación, se advierte que el estudiantado de las escuelas de la Capital tiene más información respecto a la vida universitaria. No obstante, la mayoría (el 90\%) no piensa en seguir una carrera acorde a la especialidad elegida. Esto se manifiesta especialmente en el caso de las mujeres que cursan Informática. Además, llama la atención un grupo de jóvenes que aspira a ingresar a la policía o a las fuerzas armadas. Esta idea está asociada a la percepción de la necesidad de empezar a trabajar ni bien terminan la secundaria. En este sentido, a diferencia de lo que ocurre con quienes finalizan este nivel en la secundaria orientada, la totalidad de estudiantes de estas tres escuelas consideran que trabajarán ni bien se reciban:

Para ir a la facultad necesitás muchos materiales de estudio, apuntes, libros, fotocopias, uniforme, depende de la carrera. También si es en otra provincia hay que pagar el pasaje (Estudiante mujer, EST 1)

Necesito trabajar para estudiar y a veces esto lleva a que uno deje el estudio. En nuestro caso lo que queremos estudiar está en Resistencia [a $20 \mathrm{~km}$.], y tenemos que trasladarnos hasta allá. Es un gasto. Vamos a tener que comer allá, más las fotocopias (Estudiante mujer, EST 3).

Estudiar y trabajar forman parte de los proyectos de vida que construyen estos jóvenes, tanto varones como mujeres, y constituyen momentos vitales en el proceso de independencia de los adultos:

Una vez que finalice la secundaria me gustaría independizarme y hacerme cargo de mis responsabilidades (Estudiante varón, EST 1).

Ser independiente sería no generar un gasto a la familia, liberarlos un poco, manejar tus tiempos. No tener hijos todavía hasta tener un trabajo estable y ser más grandes. Depender de uno mismo (Estudiante mujer, EST 3). 
En lo que se refiere a los escenarios laborales futuros, el estudiantado opina que las mujeres no tendrán las mismas oportunidades que los varones debido a la mentalidad de quienes emplean, aunque tengan la misma certificación. Al respecto, Bloj (2017) señala que los estereotipos culturales y las prácticas hegemónicas que atraviesan tanto a hombres como a mujeres son una de las principales barreras para el acceso al mercado de trabajo, y, en los casos en que se sortean, obligan a las mujeres a "demostrar" capacidades constantemente.

Así, es posible pensar en el orden simbólico de género, el cual organiza y da forma a los procesos educativos, al mundo del trabajo y al modo en que las subjetividades se vinculan a dicha organización estructural y simbólica (Millenaar, 2018):

Entrevistadora: ¿Al salir de la escuela, piensan que van a tener las mismas oportunidades laborales que los varones?

Estudiante: En la parte técnica no, para mí no. Para los chicos sí, porque no van a confiar en nosotras...van a confiar más en el varón que en nosotras, porque así lo ve la sociedad afuera. No sé por qué se ve que la mujer tiene que estar de recepcionista en una oficina o algo de eso y el hombre es el que tiene que estar trabajando de electricista y esas cosas, ...yo creo que es por eso, eso es lo que tiene la gente en la cabeza, eso es lo que cree (Estudiante mujer, EST 2).

Entrevistadora: ¿Ustedes creen que las mujeres tienen las mismas oportunidades laborales que los varones en esta especialidad?

Estudiante: No sé, dependería si no es una persona [refiriéndose a los de afuera] de mente cerrada (Estudiante varón, EST 2).

Respecto a las expectativas familiares, la totalidad de estudiantes comenta que desea trabajar para independizarse de la familia de origen. No mencionan el deseo o la intención de formar una nueva familia.

En síntesis, las herramientas de que dispone la juventud para elaborar un proyecto futuro varían según la escuela. Una primera distinción se encuentra entre las escuelas de capital y las del interior. Tanto varones como mujeres de las escuelas de la capital tienen la firme convicción de estar preparándose para continuar su formación en la universidad y conocen las reglas de juego de la educación superior. En cambio, los jóvenes de la escuela técnica del interior no manifiestan la posibilidad de continuar estudios superiores. El futuro aparece como más incierto para las alumnas, ya que tampoco visibilizan la oportunidad de insertarse laboralmente. De todos modos, así como lo manifiesta Seoane (2013), serán los 
estudios de inserción los que corroborarán si efectivamente las expectativas futuras de los jóvenes se cumplen y si la especial preparación alcanzada en la escuela técnica genera una ventaja adicional comparada con jóvenes que cursaron otra orientación o modalidad de la escuela secundaria.

\subsection{Formación profesional}

En el grupo de cursantes de FP hay una variedad de edades entre los 18 y los 56 años. La mayoría tiene secundaria (55\%). Son menos quienes tienen estudios superiores (24\%). En general, residen en la localidad donde se encuentra el CFP. Viven, principalmente, en hogares nucleares completos (29\%). La mitad del grupo trabaja en actividades no vinculadas con los cursos que están haciendo (53\%).

\subsubsection{Motivación de la elección del curso}

Independientemente del sexo, hay una variedad de motivaciones que inciden en la elección del curso: como complemento de la formación, para adquirir puntaje que le permita ascender en el trabajo que tienen, para utilizar lo aprendido en el hogar y/o en el trabajo, por motivación personal. Millenaar (2016) encontró esta diversidad de intereses solo para el caso de las mujeres, pero en el estudio que acá se presenta también se advierte en los varones:

Por el certificado, en mi caso para complementar el título porque yo soy profesora de informática y es una experiencia más para mí... (Cursante mujer, CFP 1).

Entonces voy sumando puntos... para ir ascendiendo... (Cursante varón, CFP 1).

Todo el estudiantado manifiesta sentirse apoyado y acompañado por sus familias (padres, madres, hermanos, hermanas, parejas) para poder estudiar y, en este sentido, consideran que las actividades vinculadas con el cuidado de hijos e hijas y las tareas del hogar están repartidas:

Tengo la suerte de poder dejarle los chicos a mi marido, él me acompaña (Cursante mujer, CFP 1).

En mi caso me apoya mi hermano, por ejemplo, si no estoy viniendo al curso me pregunta qué me pasa, que por qué no vengo y me dice que cuanto más cursos tengo y más títulos, es mejor para mí (Cursante mujer, CFP 1). 
... porque tengo también a mi esposa que estudia en la facultad. O sea, si ella llega primero que yo, se encarga de cocinar y de darle de comer a los chicos o si llego primero a mí me toca cocinar (Cursante varón, CFP 2).

Históricamente, en la cultura occidental los hombres tenían la responsabilidad del trabajo fuera del hogar, mientras que para la mujer estaba reservado el cuidado del hogar y los hijos. Así, los roles asignados a los varones -orientación hacia el trabajo, energía, racionalidad- acabaron siendo propios del estereotipo masculino, mientras que las cualidades de sensibilidad, calidez, suavidad, construyeron el estereotipo femenino. Se entiende por estereotipo "aquellas creencias populares sobre los atributos que caracterizan a un grupo social" (González Gavaldón, 1999, p. 82). Los estereotipos de género son "creencias consensuadas sobre las diferentes características de los hombres y mujeres en nuestra sociedad" (González Gavaldón, 1999, p. 82). Este conjunto de creencias tiene una gran influencia en el individuo, en su percepción del mundo y de sí mismo y en su conducta.

Las justificaciones del mantenimiento de esta desigualdad se han centrado en las diferencias fisiológicas y psicológicas existentes entre ambos sexos. Teniendo en cuenta lo registrado en los grupos focales, se observa un cambio progresivo en los roles de hombres y mujeres. Cada vez hay más mujeres que trabajan y estudian fuera del hogar y hombres que comparten con sus compañeras las tareas del hogar y el cuidado de los hijos. Esto no siempre se presenta de este modo, una investigación realizada por Milleneaar (2017) sobre políticas de empleo con enfoque de género, da cuenta de casos de falta de apoyo familiar cuando las mujeres intentan incursionar en cursos considerados tradicionalmente masculinos. En este sentido, sostiene la autora que si ya es complejo convocar a mujeres a este tipo de formación, las resistencias encontradas en sus vínculos personales y familiares vuelven aún más difícil la decisión de sostener el curso.

\subsubsection{Valoración de la formación recibida}

La totalidad de cursantes valoran positivamente la formación recibida, es más, consideran negativo perder horas de clases ya que tienen pocos días:

No me gustaba cuando no teníamos clases. Yo propongo recuperar esas horas. Nosotros tenemos dos días en la semana. Esos eran los días más lindos de la semana (Cursante mujer del CFP 3). 
El ámbito privilegiado de las clases de FP es el taller. La palabra taller proviene del francés atelier y hace referencia al lugar donde se trabaja principalmente con las manos. El concepto tiene diversos usos según el ámbito, por ejemplo: en las artes gráficas, un taller es un lugar físico donde se llevan a cabo tareas vinculadas con el grabado, el dibujo y la elaboración de todo tipo de elementos visuales. En el campo de la educación, se habla de talleres para hacer referencia a una cierta metodología de enseñanza que combina la teoría y la práctica, conecta el conocimiento con la experiencia y/o práctica profesional, y fomenta el trabajo colaborativo entre docentes-estudiantes y estudiantes-estudiantes (Maya Betancourt, 2007). En general, los sentidos que cursantes varones y mujeres otorgan a los talleres están asociados a lo manual, no a los procedimientos cognitivos puestos en juego:

[...] como esto es práctico, las clases no son escribir, anotar, son más prácticas, más contextualizadas, más didácticas serían y me encantan (Cursante varón del CFP 1).

Entrevistadora: ¿Y vos notas la diferencia en algo que aprendiste acá y no lo aprenderías viendo videos?

Cursante: Esto es práctica. Lo otro es teoría y esto es práctica. Y la práctica no se olvida uno más. Y obviamente porque en el video te muestra pero no tenés la máquina. Y acá tenés la máquina.

Y también porque acá te enseñan. En tu casa, un descuido mental o algo, la amoladora o la máquina, te puede volar un dedo o te puedes cortar.

Cuando estás viendo en el video decís "tan fácil es" pero cuando te vas a lo práctico notas la diferencia, no es lo mismo, no salió como salió en el video pero después a medida que vas aprendiendo y te vas relacionado con las máquinas, te va saliendo (Cursante varón del CFP 2).

Respecto a sus percepciones sobre el género en los espacios de taller, varones y mujeres se perciben en igualdad de condiciones. En la mitad de los casos, manifiestan diferencias en cuanto a los conocimientos previos, pero señalan que luego se equiparan durante la formación:

Yo creo que es lo mismo. En el caso de las herramientas ellas nunca agarraron un tester, una pinza y sin embargo acá ellas agarran y arman... Como ya te digo había cosas que no conocían y ahora ya estamos todos iguales (Cursante varón del CFP 1). 
Acerca de las diferencias en cuanto a los conocimientos previos, resultados similares encontró Millenaar (2017) en un estudio sobre mujeres que incursionaron en cursos de mecánica de motos en un CFP. La autora menciona que, en algunos casos, se burlaban de las cursantes, en otros, le asignaron un estudiante varón tutor para enseñar "cosas obvias" y en otros separaron a varones de mujeres por sus distintos niveles de conocimientos previos. En este estudio, todos los cursantes (de ambos sexos) señalan diferencias en cuanto a cualidades características de hombres y mujeres, a veces como complementarias y otras como desigualdades. Son las mujeres quienes encuentran desigualdades en cuanto a carencias y dificultades que tienen por considerarse ellas mismas el sexo "débil":

A veces ellas nos ayudaban con los materiales o para hacer algo, tienen más imaginación que nosotros y parece que hace falta la mano de una mujer, parece que nosotros somos más duros, más fuertes y ellas son más detallistas (Cursante varón del CFP 2).

Con el tema de la electricidad por ejemplo tratan de que las mujeres no nos quememos, de que no quedemos pegadas, pero te dicen "hacelo así", "no tengás miedo", hasta que te agarra confianza (Cursante mujer del CFP 1).

Por ahí cuando hay que hacer reparación de redes hay que subir al techo y hay que ver los cables y yo por ejemplo me muero de vértigo... (Cursante mujer del CFP 1).

Las cursantes identifican algunos estereotipos de género en el discurso de los docentes varones, en el cual aparecen subrepticiamente chistes respecto a la limpieza, el perfume, las uñas pintadas. Los chistes están asociados a los estereotipos, los prejuicios y la discriminación. Según Lipp (citado por Freud, 2008), un chiste es una provocación consciente y hábil de la comicidad, sea ésta la intuición o de la situación. Hay chistes de varios tipos: unos ingenuos o benignos, parte del humor blanco, y otros tendenciosos o agresivos. Estos últimos pueden ser denigratorios hacia algo, alguien, un grupo, institución o creencia (Bergson, 2008), algo que humilla o denigra, en este caso a "los otros" o a "las otras", los diferentes, extranjeros, un grupo social o étnico, pueblo o cultura, pobres o ricos, a las mujeres o a los hombres. Así, los chistes contienen y transmiten estereotipos y prejuicios, y desencadenan actitudes discriminatorias en formas discursivas y simbólicas (Fernández Poncela, 2011): 
Con el profe nos re cargamos... Yo soy la única mujer y él me dice "no me vengas acá con desodorante..." siempre me cargaba.

Nunca se me ocurrió tampoco, sé respetar el espacio, sé que es un lugar que no tiene que estar impecable. Lo que pasa es que en una oportunidad abrieron la máquina y tenía telaraña como que fuera la casa de Frankenstein. Entonces, yo me puse a sacar... [y el profesor me dijo] "no, no me vengas acá..." y yo le dije sólo porque era la máquina por lo demás no me molesta que los bancos estén rotos, que la mesa tenga tierra no me molesta, que haya polvillo, no me molesta nada.

Yo, fíjate, siempre venía con las uñas pintadas, hasta que empezamos a trabajar y a lijar. Obvio que ya no me podía pintar más, entonces, todos me cargaban...

Antes, venía con camisa, porque todos te decían acá... yo no me siento provocativa ni nada. Pero acá te decían que tenías que venir como para trabajar (Cursante mujer del CFP 3).

El tema de las uñas pintadas aparece en el discurso de muchas personas de la modalidad de ETP como un hábito que es un problema para las mujeres. En muchas escuelas secundarias comunes, el reglamento de convivencia tampoco permite ir con las uñas pintadas al estudiantado. Algo que llama la atención, es que no les preocupe, por ejemplo, que lleven anillos a los talleres porque esto sí puede resultar peligroso.

\subsubsection{Expectativas educativas, laborales y familiares}

Con la intención de identificar los aspectos que componen el proyecto de vida de cursantes de ambos sexos de los CFP, en los grupos focales se contempla un bloque de preguntas dirigidas a relevar expectativas futuras en relación con el estudio, el trabajo y la familia. Respecto a las expectativas futuras de formación, la totalidad de cursantes manifiesta querer seguir estudiando otro curso vinculado con el que están realizando, que les aporte más conocimientos. Además, buscan que sean útiles tanto para sus trabajos actuales como para realizar tareas en el hogar:

Seguir haciendo otras cosas, ver si hay un segundo nivel y seguir haciendo otros cursos para aprender nuevos conocimientos (Cursante varón del CFP 1).

Me gustaría hacer otro curso, capaz electricidad para la casa que es más útil (Cursante varón del CFP3). 
Me gustaría seguir estudiando para aprender más cosas y ganar más práctica (Cursante mujer del CFP 1).

En lo que se refiere a los escenarios laborales futuros, tanto varones como mujeres opinan que a pesar de que las mujeres desarrollarán las mismas capacidades y tendrán las mismas certificaciones que sus pares masculinos, les resultará más difícil o no tendrán las mismas oportunidades laborales debido a la mentalidad de las personas empleadoras. Sin embargo, consideran que la brecha se va acortando:

Yo creo que es más corta esa brecha, que ahora hay muchos oficios que son de los dos, por ejemplo peluquería (Cursante mujer, CFP 1).

Por ejemplo el réferi. Ahora hay una chica de réferi. De a poquito las mujeres se van incorporando en trabajos que eran más de hombres, sobre todo en los países más grandes. La carpintería también es más de hombres por la fuerza y lo administrativo es más un trabajo típico de la mujer. Pero las mujeres están cambiando de a poquito la sociedad (Cursante varón, CFP 1).

Sé que a las mujeres les cuesta un poco más conseguir trabajo, porque se fijan si son casadas, si tienen hijos, si está embarazada. Todo eso le interesa a un empresario (Cursante varón, CFP 1).

Eso ya depende de la sociedad, de la cultura sobre todo, de la mentalidad de la gente porque una cosa es el curso y otra trabajar afuera (Cursante varón, CFP 3).

Además, algunas mujeres suponen que tienen ciertas cualidades propias del ser femenino (falta de fuerza, vértigo, miedo) que actúan como frenos para su incursión en ciertas ocupaciones:

Yo creo que depende del trabajo, por ejemplo hay trabajos que requieren de fuerza para poder realizarlos...pero no quiere decir que sólo los hombres lo puedan hacer, sino que lo hacen por la fuerza más que nada (Cursante mujer, CFP 1).

La totalidad de cursantes manifiesta querer trabajar en lo que saben hacer para ganar dinero, mantener a sus familias y devolver a las mismas los aprendizajes recibidos. Respecto a las expectativas familiares, se infiere que no hay un futuro proyectado porque la familia es un presente, representa un soporte, una ayuda para quienes están cursando: 
Nosotros, por ejemplo, entramos sin conocimientos a los cursos de carpintería y de electricidad y ahora no pagamos mano de obra, hacemos nosotros. Y como dijo él, lo hacemos por nuestra familia y otros lo hacen para ayudar al sustento familiar (Cursante varón del CFP 2).

A futuro me gustaría conseguir otra cosa por el tema de estar en blanco, la obra social de las criaturas... (Cursante varón, CFP 3).

En síntesis, en el caso de la FP, la totalidad de cursantes adquieren recursos materiales y simbólicos de utilización inmediata en sus vidas cotidianas. No se plantean expectativas a largo plazo.

\subsection{Comparación de la perspectiva de género en EST y CFP}

A partir de lo presentado anteriormente, en este apartado se identifican similitudes y diferencias acerca de los motivos que incidieron en la elección de la escuela, la especialidad o el curso, la valoración de la formación recibida y las expectativas educativas, laborales y familiares con el fin de comparar cómo se presenta la perspectiva de género en EST y CFP, desde la mirada del grupo seleccionado para este estudio.

Respecto a los motivos que incidieron en la elección de la especialidad o el curso, en el caso de la EST, hay una mayor homogeneidad. La mayoría eligió la escuela y la especialidad por la rápida inserción laboral (55\%). Sin embargo, en FP, hay una variedad de motivos: complemento de la formación, ascenso laboral, utilización de lo aprendido en el hogar y motivación personal.

Se advierte una diferencia sustancial en cuanto al apoyo familiar. La mitad de las mujeres de EST señalan que no contaron con el apoyo de sus progenitores (principalmente los masculinos) para la elección de la escuela y/o de la especialidad porque las consideran para hombres. En cambio, en cursantes de FP, el apoyo familiar se da tanto en varones como en mujeres y entre varias generaciones (padres, madres, parejas, hijos e hijas).

Tanto cursantes de EST como de CFP valoran positivamente la formación recibida, principalmente el espacio de taller y, en él, las tareas manuales. En EST, en segundo lugar, mencionan la socialización entre pares.

En cuanto a la perspectiva de género, en la EST tanto varones como mujeres se perciben en igualdad de condiciones, pero consideran que los docentes del sexo masculino 
perciben diferencias y generan prácticas educativas disímiles. Los compañeros varones consideran estas actitudes como de cuidado y las mujeres como de discriminación.

Los varones de FP perciben desigualdades en el inicio de la formación con respecto a las mujeres. Sin embargo, consideran que se equiparan durante el proceso educativo. Las mujeres, en cambio, se perciben como desiguales durante todo el proceso formativo, con carencias culturalmente adjudicadas a su género, pero que ellas perciben como innatas. En FP ninguno de los cursantes, tanto varones como mujeres, habla de propuestas formativas diferenciadas según sexo. Solo que los docentes varones refuerzan las diferencias subrepticiamente con los chistes.

Respecto a las expectativas educativas futuras, la mayoría de estudiantes varones y mujeres de EST (90\%) considera que seguirá una carrera diferente a la especialidad que está cursando y la totalidad de cursantes de FP opina que continuará realizando otros cursos.

En lo que se refiere a expectativas laborales, el estudiantado de EST manifiesta que trabajará una vez que se reciba. En cambio, el de FP ya está trabajando y utiliza lo aprendido para realizar tareas en el hogar, en su propio trabajo o afuera para el sustento de la familia.

Tanto cursantes de EST como de FP consideran que las mujeres no tendrán las mismas oportunidades laborales que los varones debido a la mentalidad de los empleadores. En el caso de FP, esto es reforzado con las percepciones de las mujeres sobre sí mismas.

Finalmente, hay una diferencia fundamental en las expectativas familiares. El grupo de estudiantes de EST manifiesta la intención de independencia de la familia de origen y no mencionan deseos de constituir una propia. En cambio, el grupo de cursantes de FP considera que la familia es el presente y constituye un soporte fundamental. A continuación se sintetiza la comparación realizada supra en la Tabla 1. 
Tabla 1

Comparación de la perspectiva de género de cursantes de EST y CFP por categoría. CorrientesArgentina, 2017

\begin{tabular}{|c|c|c|}
\hline CATEGORÍA & EST & CFP \\
\hline Motivos & Rápida inserción laboral. & Variedad de motivos. \\
\hline Apoyo familiar & Falta de apoyo familiar. & Apoyo familiar. \\
\hline $\begin{array}{l}\text { Valoración de la } \\
\text { formación }\end{array}$ & \multicolumn{2}{|c|}{$\begin{array}{l}\text { Positivo } \\
\text { Práctica }\end{array}$} \\
\hline Género & $\begin{array}{l}\text { Autopercepción de igualdad de } \\
\text { condiciones (estudiantes). } \\
\text { Desigualdades en cuanto a } \\
\text { características femeninas y } \\
\text { masculinas - defectos (docentes). }\end{array}$ & $\begin{array}{l}\text { Desigualdades al inicio de la formación } \\
\text { y equiparación posterior (varones). } \\
\text { Desigualdades en cuanto a } \\
\text { características femeninas y masculinas } \\
\text { - defectos (mujeres y docentes). }\end{array}$ \\
\hline $\begin{array}{l}\text { Expectativas } \\
\text { educativas }\end{array}$ & $\begin{array}{c}\text { Piensan seguir una carrera } \\
\text { diferente a la especialidad elegida. }\end{array}$ & $\begin{array}{c}\text { Piensan seguir haciendo otros cursos } \\
\text { de FP. }\end{array}$ \\
\hline $\begin{array}{l}\text { Expectativas } \\
\text { laborales }\end{array}$ & $\begin{array}{l}\text { Consideran que trabajarán ni bien } \\
\text { se reciban. } \\
\text { Las mujeres no tendrán las mismas } \\
\text { oportunidades laborales que los } \\
\text { varones debido a la mentalidad de } \\
\text { los empleadores. }\end{array}$ & $\begin{array}{l}\text { Utilizan lo aprendido en trabajos en el } \\
\text { hogar o afuera para el sustento de la } \\
\text { familia. } \\
\text { Las mujeres no tendrán las mismas } \\
\text { oportunidades laborales que los } \\
\text { varones debido a la mentalidad de los } \\
\text { empleadores y de las mismas mujeres. }\end{array}$ \\
\hline $\begin{array}{l}\text { Expectativas } \\
\text { familiares }\end{array}$ & $\begin{array}{l}\text { Independencia. } \\
\text { Sin mención de formar una nueva } \\
\text { familia. }\end{array}$ & La familia es un soporte. \\
\hline
\end{tabular}

Fuente: Elaboración propia, 2018.

\section{Conclusiones}

La posibilidad que creó la Ley Nacional de Educación Técnico Profesional № 26.058 del 2005, de contar con fondos, procesos de fortalecimiento institucional y la homologación de títulos y certificaciones cambiaron las condiciones de funcionamiento de las EST y los CFP. A los cambios normativos, se suma la mayor demanda social en torno a los derechos de las mujeres, lo que constituye un trasfondo en el cual las instituciones de esa modalidad intervienen con sus propuestas educativas. Esto puede entenderse como una consecuencia de las luchas de los movimientos feministas en Argentina, que logró instaurar un discurso basado en la ampliación de derechos y el reconocimiento de las diferencias de género en los espacios educativo y laboral. No obstante, el cambio en las actitudes respecto a la desigualdad de género no se percibe con la misma intensidad cuando se indagan prácticas concretas. 
En las páginas anteriores se presentaron los principales resultados de los grupos focales realizados con cursantes (varones y mujeres por separado) de tres EST y tres CFP. El objetivo fue analizar, a partir de sus reflexiones, cómo se presenta la perspectiva de género en las especialidades y los cursos seleccionados, en relación con los motivos que incidieron en la elección de la escuela, la especialidad o el curso, la valoración de la formación recibida y las expectativas educativas, laborales y familiares.

Con el foco puesto en los mencionados grupos se muestran los contrastes y diferencias que se observan en relación con el género, tanto hacia el interior de las instituciones educativas como de sus expectativas futuras. Estas discrepancias son productos de prácticas diferenciadas de varones y mujeres en relación con la formación, con el trabajo (es decir, una "oferta" que responde a múltiples y complejos procesos de socialización, experiencias de formación, y vínculos con el empleo), así como también con la construcción de territorios masculinos y femeninos en el mercado laboral (es decir, una "demanda" que discrimina y segrega). Esto se suma a la diferencia fundamental respecto a la perspectiva de género de las propias mujeres, ya que las de secundaria manifiestan un mayor conocimiento de sus derechos, sus capacidades, sus posibilidades y una actitud reactiva frente a las oposiciones que generan las personas adultas (docentes y familiares), a diferencia de los discursos de las mujeres de FP, que si bien tímidamente reconocen sus potencialidades, tuvieron la valentía de ingresar a esos cursos considerados tradicionalmente masculinos.

Históricamente, la ETP se caracterizó por presentar rasgos de discriminación sexista y por reproducir, en sus aulas, la división sexual del trabajo cristalizada culturalmente. Sin embargo, las mujeres se fueron introduciendo de manera gradual, aunque todavía resulta difícil su inserción en el mercado laboral.

En tal sentido, se considera que por un lado, la ampliación del cupo femenino en las especialidades y cursos considerados tradicionalmente masculinos es un avance importante para ir limando las diferencias y revisar los estereotipos de género vinculados con las desigualdades en la formación recibida y la división sexual del trabajo, así como también lo sería la realización de talleres de sensibilización de género (tanto para cursantes como para docentes) en instituciones educativas similares. Por otro lado, si bien se sostiene que las políticas de formación no tienen la responsabilidad de la generación de empleo, sí podrían apoyar a las personas para que se transformen en detectoras de oportunidades, pasando del 
estatus de sujetos pasivos, dependientes de una intervención externa que los acerque a una oferta de trabajo insuficiente, al de constructoras de su estrategia de empleabilidad.

Finalmente, el análisis realizado invita a retomar las discusiones sobre la complejidad de la organización del género en relación con las prácticas y representaciones, e interrogar y leer, en las acciones aparentemente neutras, huellas de inequidad que invitan a asumir que vale la pena dar batalla.

\title{
6. Referencias
}

Bergson, Henri. (2008). La risa. Ensayo sobre la significación de lo cómico. Madrid, España: Alianza Editorial.

Bloj, Cristina. (2017). Trayectorias de mujeres Educación técnico-profesional y trabajo en la Argentina. CEPAL - Serie Asuntos de Género, 145, Santiago, Chile: Naciones Unidas. Recuperado de https://www.cepal.org/es/publicaciones/41230-trayectorias-mujereseducacion-tecnico-profesional-trabajo-la-argentina

Conde, Analaura. (2013). Educación técnica y género en Uruguay: ¿Una realidad que se transforma? (Tesis de maestría inédita). Universidad de la República, Montevideo, Uruguay. Recuperado de https://www.colibri.udelar.edu.uy/jspui/bitstream/123456789/7668/1/TMS CondeAnalau $\underline{\text { ra.pdf }}$

Córica, Agustina. (2015). Juventud y futuro: expectativas educativas y laborales de los estudiantes de la escuela secundaria. En $12^{\circ}$ Congreso Nacional de Estudios del Trabajo. El Trabajo en su Laberinto. Viejos y Nuevos Desafíos. Buenos Aires, Argentina: Universidad de Buenos Aires, Facultad de Ciencias Económicas, Asociación Argentina de Especialistas en Estudios del Trabajo (ASET). Recuperado de http://www.aset.org.ar/2015/ponencias/7 Corica.pdf.

Dubet, François. (2006). El declive de la institución. Profesiones, sujetos e individuos ante la reforma del Estado. Barcelona, España: Gedisa.

Fernández Poncela, Anna María. (2011). Prejuicios y estereotipos. Refranes, chistes y acertijos, reproductores y transgresores. Revista de Antropología Experimental, 11(22),

\author{
317-328. Recuperado
}

http://revista.ujaen.es/huesped/rae/articulos2011/22fernandez11.pdf

Freud, Sigmund. (2008). El chiste y su relación con el inconciente. Madrid, España: Alianza Editorial.

Gallart, María Antonia., Miranda, Martín., Peirano, Claudia. y Sevilla, María Paola. (2003). Tendencias de la educación técnica en América Latina. Estudios de casos en Argentina y Chile. Santiago, Chile: UNESCO, Instituto Internacional de Planeamiento Educativo. 
Gamba, Susana (Cood.). (2007). Diccionario de estudios de género y feminismos. Buenos Aires, Argentina: Biblos.

Gobierno de Argentina, Instituto Nacional de Estadísticas y Censos. (2012). Censo Nacional de Población y Vivienda. 2010. Buenos Aires, Argentina.

González Gavaldón, Blanca. (1999). Los estereotipos como factor de socialización en el género. Comunicar, 12, 79-88. Recuperado de http://www.redalyc.org/pdf/158/15801212.pdf

Instituto Nacional de Educación Tecnológica. (2016), Demanda de Capacidades 2020. Análisis de la demanda de capacidades laborales en Argentina. Buenos Aires, Argentina: Autor. Recuperado de http://www.inet.edu.ar/wpcontent/uploads/2016/06/2016.06.21 Informe Demandas Laborales 2020 vf.pdf

Instituto Nacional de Educación Tecnológica. (2018). Mujeres en la ETP: desigualdades y oportunidades, Buenos Aires, Argentina: Autor.

Lavigne, Luciana. (2009). Entre el deseo y la regulación: poéticas y políticas del rostro, ponencia presentada en el VIII RAM (Reunión de Antropología del Mercosur). Diversidad y poder en América Latina. Buenos Aires, Argentina.

León, Fernanda. (2009). Mujeres y discurso pedagógico en la escuela técnica. En A. Villa (coord.), Sexualidad, relaciones de género y de generación. Perspectivas históricoculturales en educación (pp. 171-211). Buenos Aires, Argentina: Noveduc.

Ley de Educación Técnico Profesional № 26058, del 7 de septiembre. (2005). Buenos Aires, Argentina: Gobierno de la Argentina. Poder Legislativo.

Maya Betancourt, Arnobio. (2007). El taller educativo. ¿Qué es? Fundamentos, cómo organizarlo, cómo dirigirlo y cómo evaluarlo [2 $2^{\mathrm{a}}$ Ed.]. Bogotá, Colombia: Cooperativa Editorial Magisterio.

Millenaar, Verónica. (2016). Trayectorias educativo-laborales de varones y mujeres jóvenes de sectores populares que participan de dispositivos de formación para el trabajo (Área Metropolitana de Buenos Aires, 2008-2014). Entre la profesionalización, la acumulación y la socialización (Tesis de doctorado inédita). Universidad de Buenos Aires, Buenos Aires, Argentina.

Millenaar, Verónica. (2017). Políticas de empleo con enfoque de género: formación laboral en oficios no tradicionales para mujeres. Cadernos Pagu, 51, e175114. doi: $10.1590 / 18094449201700510014$

Millenaar, Verónica. (2018). Mujeres y varones ¿caminos laborales diferentes? La orientación y la formación para el trabajo en la escuela secundaria desde una perspectiva de género. En S. Martínez (Comp.), Conversaciones en la escuela secundaria. Política, trabajo y subjetividad (pp. 141-160). Neuquén, Argentina: Universidad Nacional del Comahue. 
Morgade, Graciela. (2001). Aprender a ser mujer. Aprender a ser varón. Buenos Aires, Argentina: Novedades Educativas.

Pérez Moreno, Elena Silvia. (2013). El lugar de las alumnas dentro de una escuela técnica Secundaria de la ciudad de Córdoba. En 2do. Congreso Interdisciplinario de Género y Sociedad. Córdoba, Argentina: Universidad Nacional de Córdoba. Recuperado de conferencias.unc.edu.ar/index.php/ponencias/ponencias2013/paper/view/1884/591

Seoane, Viviana Isabel. (2012). Sexismo y androcentrismo en la escuela técnica: Experiencias de mujeres jóvenes en torno a la sexualidad, el género y la condición juvenil. En VII Jornadas de Sociología. La Plata, Argentina: Universidad Nacional de La Plata. Recuperado http://www.memoria.fahce.unlp.edu.ar/trab eventos/ev.2266/ev.2266.pdf

Seoane, Viviana Isabel. (2013), Género, cuerpo y sexualidades. Experiencias de mujeres en escuelas técnicas de la ciudad de La Plata (Tesis de doctorado, Facultad Latinoamericana de Ciencias Sociales). Facultad Latinoamericana de Ciencias Sociales (FLACSO), Buenos Aires, Argentina.

Silveira, Sara. (2001), La dimensión de género y sus implicaciones en la relación entre juventud, trabajo y formación. En E. Pieck (Coord.), Los jóvenes y el trabajo: la educación frente a la exclusión social (pp. 457-492). México: UIA, IML, UNICEF, CINTERFOR, OIT, RET y CONALEP. Recuperado de http://www.oitcinterfor.org/node/7107

Silveira, Sara. (2011). Género, trabajo y formación profesional: Una realidad interdependiente y mutuamente modificante. Género y trabajo. Avances y desafíos pendientes, 4 4, 4. 4 Recuperado de https://www.oitcinterfor.org/sites/default/files/file publicacion/AyA\%2011.pdf

Sobrevila, Marcelo Antonio. (1995). La Educación Técnica Argentina. Buenos Aires, Argentina: Academia Nacional de Educación.

Sweet, Richard. (2006). Los desafíos que enfrenta la educación técnica profesional en Chile: lecciones de la experiencia internacional. En III Seminario Internacional DesarrollaT: Trazando el camino de la Educación Media TP en Chile. Santiago, Chile.

Tavela, Danya. y Catino, Magalí. (2018), Áreas de vacancia, vinculación, pertinencia y planificación del sistema universitario: una herramienta para abordar la expansión de la educación superior en territorio. Buenos Aires, Argentina: Ministerio de Educación de la Nación. Recuperado https://www.argentina.gob.ar/sites/default/files/archivetempareas de vacancia vincula cion pertinencia y planificacion del sistema universitario.pdf 
Revista indizada en

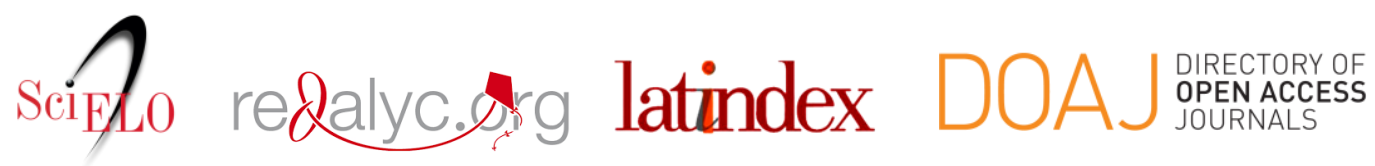

Distribuida en las bases de datos:

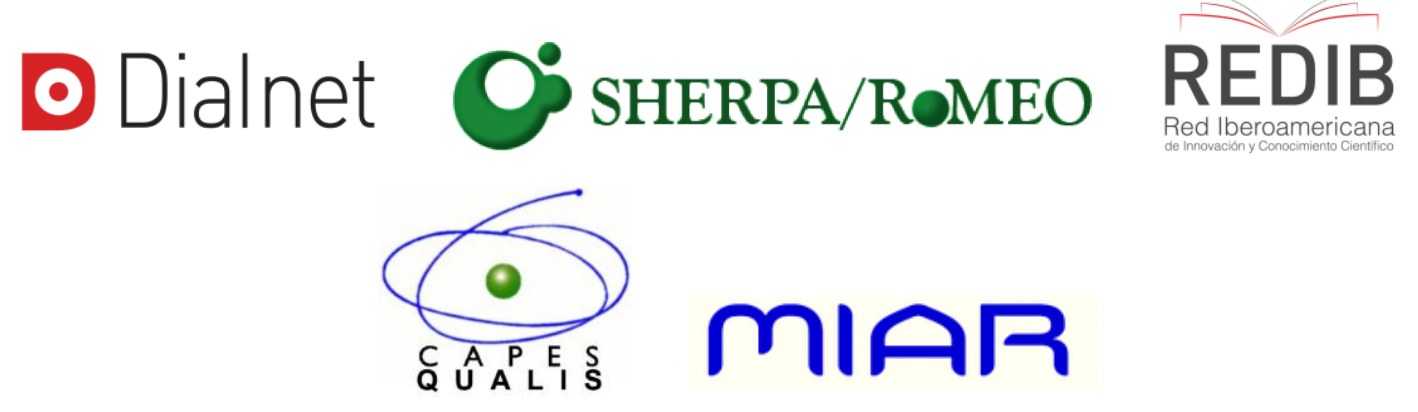

